\title{
Erratum to: Bigger mothers = better chances: the first test of a central hypothesis in marine fish ecology-editorial comment on the feature article by Saenz-Agudelo et al.
}

\author{
Myron A. Peck ${ }^{1} \cdot$ Peter M. Buston ${ }^{2}$
}

Published online: 18 November 2015

(C) Springer-Verlag Berlin Heidelberg 2015

Erratum to: Mar Biol (2015) 162:1-2

DOI 10.1007/s00227-014-2567-7

In the original publication of the article, Dr. Peter N. Buston is missing in the author group. The correct author group and affiliation is given in this erratum.

The online version of the original article can be found under doi:10.1007/s00227-014-2567-7.

Myron A. Peck

myron.peck@uni-hamburg.de

1 Center for Earth System Research and Sustainability, Institute of Hydrobiology and Fisheries Science, University of Hamburg, Olbersweg 24, 22767 Hamburg, Germany

2 Department of Biology and Marine Program, Boston University, 5 Cummington Mall, Boston, MA 02215, USA 